\title{
Factors associated with burnout among Chinese hospital doctors: a cross-sectional study
}

\author{
Hui Wu, Li Liu, Yang Wang, Fei Gao, Xue Zhao and Lie Wang*
}

\begin{abstract}
Background: Burnout has been a major concern in the field of occupational health. However, there is a paucity of research exploring the factors related to burnout among Chinese doctors. Investigation of these factors is important to improve the health of doctors and the quality of healthcare services in China.

Methods: The study population consisted of 1,618 registered hospital doctors from Liaoning province of China. Burnout was measured using the Chinese version of the Maslach Burnout Inventory-General Survey. Occupational stress was measured using the Chinese versions of the Job Content Questionnaire and the Effort-Reward Imbalance Questionnaire. Data were collected on the respondents' demographic characteristics and work situations. Of the doctors solicited for enrollment, 1,202 returned the completed questionnaire (555 men, 647 women), giving a response rate of $74.3 \%$. A general linear regression model was applied to analyze the factors associated with burnout.
\end{abstract}

Results: The burnout mean scores were 11.46 (7.51) for emotional exhaustion, 6.93 (5.15) for cynicism, and 24.07 (9.50) for professional efficacy. In descending order of standardized estimates, variables that predicted a high level of emotional exhaustion included: high extrinsic effort, dissatisfaction with doctor-patient relationship, high overcommitment, working $>40 \mathrm{~h}$ per week, low reward, and high psychological job demands. Variables that predicted a high level of cynicism included: high extrinsic effort, low reward, dissatisfaction with doctor-patient relationship, high overcommitment, low decision authority, low supervisor support, and low skill discretion. Variables that predicted a low perceived professional efficacy included: high psychological job demands, low coworker support, high extrinsic effort, low decision authority, low reward, and dissatisfaction with doctor-patient relationship.

Conclusions: These findings suggest that occupational stress is strongly related to burnout among hospital doctors in China. Strategies that aim to improve work situations and decrease occupational stress are necessary to reduce burnout, including health education, health promotion, and occupational training programs.

Keywords: Burnout, Doctors, Maslach Burnout Inventory-General Survey, Occupational stress

\section{Background}

Burnout is defined as "a syndrome of exhaustion, cynicism and low professional efficacy" [1]. Researchers and administrators are increasingly recognizing the problem of burnout, which has been a major concern internationally in the field of occupational health [2-5]. Studies have found that burnout may lead to increased rates of absenteeism and turnover, and decreased job performance, commitment, career satisfaction, and productivity [6-10].

\footnotetext{
* Correspondence: liewang@mail.cmu.edu.cn

Department of Social Medicine, School of Public Health, China Medical University, No. 92 Beier Road, Heping District, Shenyang, Liaoning 110001, People's Republic of China
}

As human service professionals, doctors are exposed to a range of factors such as work overload, time pressures, role conflicts, and effort-reward imbalances. Further, the relationship between doctors and patients often involves high interpersonal and/or emotional demands; this can also elevate the risk of burnout [2,10-13]. Doctors who experience burnout have a high incidence of depressive symptoms and suicide attempts, and are often unable to meet the demands of patients [14-16].

China is currently undergoing a major healthcare system reform; the focus is transforming from disease to health, and from sustaining life to quality of life. Moreover, the 
huge population base and increasing health consciousness over recent years have led to an overload of patients for Chinese doctors. In China, the ratio of doctors to the general population is $1: 735$, which is considerably lower than that of Western countries (1:280-1:640) [17]. Chinese doctors frequently experience work overload and extra shifts and, at times, disputes occur because of patient dissatisfaction with care $[13,18]$. Doctors are more likely to experience time pressures and energy deficiencies, which seem to aggravate the burnout of Chinese doctors [19].

Results from previous studies suggest that burnout among doctors is the result of exposure to a combination of factors related to their personal and working environments. These factors are believed to be demographic (age, marital status, and education) $[12,20]$ and work related (work time, work shift, and role boundaries) [20,21]. Occupational stress has been identified as the major factor associated with burnout $[11,22,23]$. Studies of occupational stress have considered various theoretical approaches, including the Job Demand-Control (JDC) model [24] and the Effort-Reward Imbalance (ERI) model [25,26]. The JDC model postulates that the source of job stress comes from two basic characteristics of the job itself: psychological job demands and job control (known in the model as 'decision latitude'), and social interactions ('social support' as per the model). Psychological strain is a consequence of the combined effects from the job's demands and control on an individual, while low social support at work further aggravates occupational stress. The ERI model emphasizes the non-reciprocal social exchange between costs and gains at work and overcommitment, which can cause a state of emotional distress and lead to adverse health outcomes. The two models complement each other in that the JDC model focuses on the task characteristics and social aspects of the workplace, while the ERI model relates to the stressful experiences and personal cognitive patterns of dealing with work. However, the association between occupational stress and burnout has received less attention, especially in relation to the combined effects of the JDC model and the ERI model. Therefore, factors from both models were included in this study.

Burnout among hospital doctors has been widely studied in Western countries. Some research has been undertaken in China to explore the factors that contribute to the burnout of doctors [13,18], where the health system and culture may result in a different experience for doctors. For example, because of patient overload in most Chinese hospitals, doctors work $40 \mathrm{~h}$ or more each week. There are no on-call doctors for sick leave or holidays [27]. In addition, the characteristics of Chinese culture are also different when compared with Western countries. There are hierarchical social rules between parents and children, and older and younger people; these rules are strictly observed in all aspects of the social lives of Chinese people [28].
During the recent health sector reforms, doctors have not only been overloaded, but their average income level has been relatively low. As a consequence, ERI could be a factor associated with burnout. In addition, doctors exhausted with their heavy patient load might have found it difficult to give patients the care they deserve. We hypothesize that the doctor-patient relationship is an important factor related to burnout. Taking into consideration the conclusions from previous studies and the different health system and culture in China, in the current study, the following factors were investigated for their association with burnout, with the aim of reducing burnout among Chinese doctors: demographics, work situations (including the doctor-patient relationship), and occupational stress (including ERI).

\section{Methods}

\section{Subjects and procedures}

China Medical University is the leading medical institution in northeast China. It has seven teaching hospitals dispersed throughout Liaoning province with a total of 1,629 registered doctors. A cross-sectional survey was conducted during May and June 2010. All seven teaching hospitals were approached; the principal investigators met with hospital administrators to share the study questionnaire. The administrators assisted in contacting the eligible doctors who had agreed to participate. After a verbal briefing from the principal investigators regarding the study goals and the information being obtained by the questionnaire, the doctors could choose whether or not to complete the study. Informed consent was obtained from participants; individualized data were kept confidential and was only used for the study's analysis. Eleven refused to participate (five men). The questionnaires were eventually distributed to the 1,618 registered doctors who agreed to participate. Because of limited available free time during work hours, the questionnaires were self-administered by the doctors and returned to the administrators. The principal investigators collected the completed questionnaires at an appointment with the administrators 1 week later. A total of 1,202 completed questionnaires were received (555 men and 647 women) yielding a response rate of $74.3 \%$.

The study was approved by the Committee on Human Experimentation at China Medical University (Senyang, Liaoning, China).

\section{Measurement of burnout}

Burnout was measured using the Chinese version of the Maslach Burnout Inventory-General Survey (MBI-GS) [1]. The MBI-GS was translated and back-translated to ensure it reflected the original message, and revised to make the items culturally and linguistically applicable to China [27]. A Chinese version of the MBI-GS has previously been used with Chinese nurses and doctors [13,18,29-31]. The 
survey includes three subscales: emotional exhaustion (EE; five items), cynicism (CY; four items), and professional efficacy (PE; seven items). Each item has seven possible answers: never, rarely (several times per year), sometimes (once a month), often (several times per month), frequently (once a week), always (several times per week), and every day. These responses were scored from 0 to 6 . The possible minimum and maximum scores were from 0 to 30 for $\mathrm{EE}$, from 0 to 24 for $\mathrm{CY}$, and from 0 to 42 for PE. Emotional exhaustion was defined as feeling emotionally overwhelmed and exhausted by work; CY was defined as doubting the value of one's work or its contribution to anything. Reduced PE described a feeling of reduced competence and a lack of success/achievement in one's work with people. The cut-off points of the MBI-GS in the Chinese version were: EE low $<$, average 9-13, high $>13$; CY - low $<3$, average 3-9, high $>9$; PE - low $>30$, average $30-18$, high $<18$. Individuals with high EE and CY scores combined with a low PE score were identified as having a high degree of burnout [27]. In this study, Cronbach alpha coefficients for EE, CY, and PE were $0.95,0.92$, and 0.88 , respectively.

\section{Demographics}

Demographics collected from each respondent included age, gender, education, and marital status. Age was classified as $\leq 30,31-40,41-50$, or $\geq 51$ years. The education classification was based on the doctors' educational experiences before they started working. In China, health workers who graduate from junior college are able to obtain a doctor's license after becoming a licensed assistant doctor and gaining experience with medical practice. As such, education was grouped into three different categories: junior college, undergraduate, and graduate. Marital status was categorized as married or single. In this study, only 13 participants (1.08\%) belonged to the "widowed/divorced" group; this group was combined with the 'single' group.

\section{Work situations}

Work situations were defined as job rank, weekly work time and doctor-patient relationship. Job rank was categorized as head doctor or staff doctor by asking the question, "Are you a head doctor or a staff doctor?" Weekly work time was divided into $\leq 40 \mathrm{~h}$ or $>40 \mathrm{~h}$, according to the current work arrangement of $8 \mathrm{~h}$ per day. Doctor-patient relationship was assessed by the question, "How often have you been dissatisfied with the doctor-patient relationship at work?" with five possible answers: never, rarely, sometimes, frequently, and always; the responses were further dichotomized into 'general dissatisfaction' (never/rarely/sometimes) or 'serious dissatisfaction' (frequently/always) [32,33].

\section{Occupational stress}

Occupational stress was measured using the Chinese version of the Job Content Questionnaire (JCQ), based on the JDC model, and the Effort-Reward Imbalance (ERI) Questionnaire, based on the ERI model. The JCQ and ERI have been reported to have good reliability and validity in the Chinese population $[34,35]$.

The 22-item JCQ has three scales: decision latitude, psychological job demands, and social support. The decision latitude scale is the sum of two subscales: skill discretion (measured by six items) and decision authority (measured by three items). The psychological job demands scale is measured by five items. The social support scale is the sum of two subscales: coworker support (measured by four items) and supervisor support (measured by four items). Responses to all the items were scored from 1 , for complete disagreement, to 4 for complete agreement. The Cronbach alpha coefficients for decision latitude, psychological job demands, and social support were $0.83,0.88$, and 0.91 , respectively.

The ERI contains 23 items that measure extrinsic effort (six items), reward (11 items), and overcommitment (six items). Each response to extrinsic effort and reward was scored from 1 to 5 ; higher total scores indicated higher demands of efforts and higher rewards. Responses to overcommitment were scored from 1, for complete disagreement, to 4 for complete agreement. Higher scores suggest higher demands characterized by excessive workrelated commitments. The Cronbach alpha coefficients for extrinsic effort, reward, and overcommitment were 0.90 , 0.81 , and 0.86 , respectively.

\section{Data analysis}

Data were analyzed using Statistical Analysis System for Windows, version 8.2 (SAS Institute Inc., Cary, NC, USA). Before the data analyses were conducted, the normal distribution of the variables was tested. The P-P-plot analyses and K-S tests of normal distribution indicated that the variables fulfilled the postulation of normal distribution. Correlations between independent variables were tested by Kappa test for the categorical variables and by Pearson correlation for the continuous variables. If the Kappa value and correlation coefficient between independent variables was more than 0.5 , these variables were regarded as having agreement and were adjusted using multivariate analysis. In this study, no agreement was found. Comparisons of MBI-GS scores for demographics and work situations were tested by the Student t-test, ANOVA, and post-hoc test. Correlations between MBI-GS scores and occupational stress were examined by Pearson correlation. Factors associated with MBI-GS scores were identified by a general linear model with adjustment for age and gender. The following variables were entered into a general linear analysis: demographics (age, education, and marital status), work situations (job rank, weekly work time, and doctorpatient relationship), and occupational stress (JDC and ERI). The effect of different variables on the variance in 
MBI-GS subscale scores was tested by hierarchical linear regression analysis. In step 1 , demographics were added. In step 2, work situations were added. In step 3, occupational stress was added. Statistical significance was defined as $p<0.05$.

\section{Results}

The average age of respondents was 38.67 (8.78) years; 38.86 (9.30) years for men and 38.51 (8.31) years for women. The burnout mean scores were 11.46 (7.51) for EE, 6.93 (5.15) for $\mathrm{CY}$, and 24.07 (9.50) for PE. Respondent distribution by demographics and work situations is shown in Table 1 . This shows that $46.2 \%$ were male and $53.8 \%$ were female, $94.3 \%$ of respondents had at least attained an undergraduate qualification, and $80.9 \%$ were married. Among all the respondents, $17.5 \%$ were head doctors, $61.9 \%$ worked $>40$ h per week, and $47.2 \%$ reported serious dissatisfaction with their doctor-patient relationships. The prevalence of a high degree of burnout was $12.1 \%$ in this study.

Univariate analysis of MBI-GS scores in relation to demographics and work situation variables are shown in Table 2. There was no significant association of burnout

Table 1 Respondent distribution by demographics and work situations

\begin{tabular}{|c|c|}
\hline Variables & N (\%) \\
\hline \multicolumn{2}{|l|}{ Age (years) } \\
\hline$\leq 30$ & $295(24.5)$ \\
\hline $31-40$ & 406 (33.8) \\
\hline $41-50$ & $375(31.2)$ \\
\hline$\geq 51$ & $126(10.5)$ \\
\hline \multicolumn{2}{|l|}{ Gender } \\
\hline male & $555(46.2)$ \\
\hline female & $647(53.8)$ \\
\hline \multicolumn{2}{|l|}{ Education } \\
\hline Junior college & $68(5.7)$ \\
\hline Undergraduate & $809(67.3)$ \\
\hline Graduate & $325(27.0)$ \\
\hline \multicolumn{2}{|l|}{ Marital status } \\
\hline Married & $972(80.9)$ \\
\hline Single & $230(19.1)$ \\
\hline \multicolumn{2}{|l|}{ Job rank } \\
\hline Head doctor & $210(17.5)$ \\
\hline Staff doctor & $992(82.5)$ \\
\hline \multicolumn{2}{|l|}{ Weekly work time (hours) } \\
\hline$\leq 40$ & $458(38.1)$ \\
\hline$>40$ & $744(61.9)$ \\
\hline \multicolumn{2}{|l|}{ Doctor-patient relationship } \\
\hline General dissatisfaction & $635(52.8)$ \\
\hline Serious dissatisfaction & $567(47.2)$ \\
\hline
\end{tabular}

scores based on gender or marital status. Age, education, job rank, weekly work time and the doctor-patient relationship were significantly related to $\mathrm{EE}$ and $\mathrm{CY}$ scores $(p<0.05)$. For age, EE was significantly lower among those aged $\geq 51$ years when compared with other groups; $\mathrm{CY}$ was significantly higher among those aged $\leq 30$ years than those aged $41-50$ and $\geq 51$ years, and CY was significantly higher among those aged 31-40 years than those aged $41-50$ and $\geq 51$ years. For education, EE was significantly higher among graduate than junior college and undergraduate groups; EE was significantly higher among undergraduate group compared with junior college group. Further, the CY scores were significantly lower among junior college group than undergraduate and graduate groups. Weekly work time and doctor-patient relationship were significantly related to PE scores $(p<0.05)$.

Correlations between MBI-GS scores and occupational stress are detailed in Table 3. The following JCQ

Table 2 Univariate analysis of MBI-GS scores in relation to demographics and work situations

\begin{tabular}{|c|c|c|c|}
\hline \multirow[t]{2}{*}{ Variables } & \multicolumn{3}{|c|}{ MBI scores (Mean \pm SD ) } \\
\hline & $\mathrm{EE}$ & $\mathrm{CY}$ & $\mathrm{PE}$ \\
\hline \multicolumn{4}{|l|}{ Age (years) } \\
\hline$\leq 30$ & $12.40 \pm 7.75^{*}$ & $7.67 \pm 5.71^{*}$ & $23.35 \pm 8.77$ \\
\hline $31-40$ & $11.88 \pm 7.16^{*}$ & $7.46 \pm 4.97^{*}$ & $23.61 \pm 9.87$ \\
\hline $41-50$ & $11.00 \pm 7.51^{*}$ & $6.28 \pm 4.95$ & $24.19 \pm 10.28$ \\
\hline$\geq 51$ & $9.26 \pm 7.64$ & $5.45 \pm 4.55$ & $25.09 \pm 9.32$ \\
\hline \multicolumn{4}{|l|}{ Gender } \\
\hline male & $11.61 \pm 7.86$ & $7.43 \pm 5.42$ & $23.57 \pm 9.39$ \\
\hline female & $11.32 \pm 7.21$ & $7.10 \pm 4.88$ & $24.49 \pm 9.58$ \\
\hline \multicolumn{4}{|l|}{ Education } \\
\hline Junior college & $8.93 \pm 6.91$ & $5.26 \pm 4.31$ & $24.18 \pm 9.39$ \\
\hline Undergraduate & $12.26 \pm 7.47^{*}$ & $7.53 \pm 5.39^{*}$ & $24.06 \pm 9.21$ \\
\hline Graduate & $13.96 \pm 7.98^{*}$ & $7.87 \pm 4.70^{*}$ & $23.79 \pm 9.86$ \\
\hline \multicolumn{4}{|l|}{ Marital status } \\
\hline Married & $11.10 \pm 7.03$ & $6.73 \pm 5.16$ & $24.26 \pm 9.45$ \\
\hline Single & $11.54 \pm 7.62$ & $6.98 \pm 5.14$ & $23.24 \pm 9.68$ \\
\hline \multicolumn{4}{|l|}{ Job rank } \\
\hline Head doctor & $9.29 \pm 7.19$ & $5.42 \pm 4.62$ & $24.19 \pm 9.60$ \\
\hline Staff doctor & $11.92 \pm 7.50^{* *}$ & $7.25 \pm 5.21^{* *}$ & $24.04 \pm 9.48$ \\
\hline \multicolumn{4}{|l|}{ Weekly work time (hours) } \\
\hline$\leq 40$ & $9.70 \pm 6.75$ & $5.77 \pm 4.61$ & $24.19 \pm 9.45$ \\
\hline$>40$ & $11.94 \pm 7.64^{* *}$ & $7.25 \pm 5.26^{* *}$ & $23.63 \pm 9.70^{* *}$ \\
\hline \multicolumn{4}{|l|}{ Doctor-patient relationship } \\
\hline General dissatisfaction & $8.24 \pm 5.84$ & $4.57 \pm 3.44$ & $24.50 \pm 9.92$ \\
\hline Serious dissatisfaction & $15.06 \pm 7.54^{* *}$ & $9.58 \pm 5.87^{* *}$ & $23.58 \pm 8.99^{*}$ \\
\hline
\end{tabular}


variables showed negative correlations with both $\mathrm{EE}$ and CY, and positive correlations with PE $(p<0.01)$ : skill discretion, decision authority, supervisor support, and coworker support. Psychological job demands had a positive correlation with EE and CY, and a negative correlation with PE $(p<0.01)$. For the ERI variables, both extrinsic effort and overcommitment showed positive correlations with EE and CY, and negative correlations with PE $(p<0.01)$. Reward had a negative correlation with EE and $\mathrm{CY}$, and a positive correlation with $\mathrm{PE}(p<0.01)$.

A general linear model analysis of the factors associated with MBI-GS scores is shown in Table 4. After controlling for age and gender, variables that predicted a high level of EE (in descending order of standardized estimate) included: high extrinsic effort, dissatisfaction with doctor-patient relationship, high overcommitment, working $>40 \mathrm{~h}$ per week, low reward, and high psychological job demands $\left(F_{16,1185}=154.82, p=0.00\right)$. Variables that predicted a high level of $\mathrm{CY}$ (in descending order of standardized estimate) included: high extrinsic effort, low reward, dissatisfaction with doctor-patient relationship, high overcommitment, low decision authority, low supervisor support, and low skill discretion $\left(F_{16,1185}=64.53\right.$, $p=0.00$ ). Variables that predicted a low level of PE (in descending order of standardized estimate) included: high psychological job demands, low coworker support, high extrinsic effort, low decision authority, low reward, and dissatisfaction with doctor-patient relationship $\left(F_{16,1185}=9.92\right.$, $p=0.00)$.

The effect of different variables on the variance in MBIGS subscale scores is detailed in Table 5. Demographic variables explained $1 \%$ of variance in $\mathrm{EE}, \mathrm{CY}$, and $\mathrm{PE}$. Work situations explained $12 \%$ of variance in EE, $10 \%$ of variance in $\mathrm{CY}$, and $6 \%$ of variance in $\mathrm{PE}$. Occupational

Table 3 Correlations between MBI-GS scores and occupational stress

\begin{tabular}{lccc}
\hline Variables & \multicolumn{3}{c}{ MBI-GS scores $(r)$} \\
\cline { 2 - 4 } & EE & CY & PE \\
\hline JCQ & $-0.11^{* *}$ & $-0.16^{* *}$ & $0.07^{* *}$ \\
Skill discretion & $-0.19^{* *}$ & $-0.24^{* *}$ & $0.09^{* *}$ \\
Decision authority & $0.39^{* *}$ & $0.21^{* *}$ & $-0.13^{* *}$ \\
Psychological job demands & $-0.22^{* *}$ & $-0.24^{* *}$ & $0.08^{* *}$ \\
Supervisor support & $-0.10^{* *}$ & $-0.15^{* *}$ & $0.11^{* *}$ \\
Coworker support & & & -0.04 \\
ERI & $0.52^{* *}$ & $0.46^{* *}$ & $0.08^{* *}$ \\
Extrinsic effort & $-0.43^{* *}$ & $-0.43^{* *}$ & $-0.10^{* *}$ \\
Reward & $0.49^{* *}$ & $0.34^{* *}$ & \\
Overcommitment & & & \\
\hline
\end{tabular}

${ }^{* *} p<0.01$.

$M B I-G S$, Maslach Burnout Inventory-General Survey.

$E E$, Emotional exhaustion; $C Y$, Cynicism; $P E$, Professional efficacy. stress was responsible for $32 \%, 22 \%$, and $7 \%$ of variance in $\mathrm{EE}, \mathrm{CY}$, and PE, respectively.

\section{Discussion}

This study explored the factors associated with burnout among hospital doctors in China. Our study subjects were drawn from seven teaching hospitals of the China Medical University, Liaoning province, which has a proportion of doctors in the health care work force (34.5\%) comparable with the national proportion of doctors (35.4\%) with the same average income level as the average national level in China [36]. The burnout mean scores were 11.46 (7.51) for EE, 6.93 (5.15) for CY, and 24.07 (9.50) for PE. The levels of EE and CY were higher than the levels of other occupations that have been previously reported in China, and the level of PE was lower than other occupations $[30,37]$. The prevalence of a high degree of burnout in this study was $12.1 \%$, which is higher than rates from other countries $[38,39]$. This finding should encourage hospital administrators to be aware about the risk of burnout. Efforts should be made to prevent and reduce burnout among Chinese doctors.

In this study, work situations explained $12 \%$ of variance in $\mathrm{EE}, 10 \%$ of variance in $\mathrm{CY}$, and $6 \%$ of variance in PE. Among the factors related to work situations, weekly work time and the doctor-patient relationship are two factors that have been shown to be related to burnout, both in this and previous studies [20,21]. Doctors in the current study who worked more than $40 \mathrm{~h}$ per week and reported dissatisfaction with doctor-patient relationship had significantly higher EE and CY scores and lower PE scores than respondents who worked fewer hours. Interestingly, $47.2 \%$ of doctors in this study reported serious dissatisfaction with their relationship with patients; this was one of the most salient factors related to high EE and CY, and low PE scores. One possible explanation is that the Chinese healthcare service has been rapidly changing over recent years, and the traditional diseasecentered care model is gradually being replaced by a patient-centered approach. Thus, many doctors' responsibilities have increased, as have their patients' demands [40]. In addition, the huge population base in China and the corresponding increase in patient numbers have created a very large work burden for doctors. As a result, doctors are working longer hours and have less time for communicating with patients, and medical disputes often occur owing to patient dissatisfaction with care $[18,41]$. These combined effects have created an increasing conflict between patients and doctors and strained the doctor-patient relationship [19,33]. As a consequence, organizational interventions such as decreasing long working hours and improving the doctorpatient relationship should be considered during the current reformation of care models [19]. 
Table 4 General linear model analysis of the factors associated with MBI-GS scores

\begin{tabular}{|c|c|c|c|c|c|c|}
\hline \multirow[t]{3}{*}{ Variables } & \multicolumn{6}{|c|}{ MBI-GS scores } \\
\hline & \multicolumn{2}{|c|}{$\mathrm{EE}$} & \multicolumn{2}{|c|}{$\mathrm{CY}$} & \multicolumn{2}{|c|}{ Low PE } \\
\hline & B & Beta & B & Beta & B & Beta \\
\hline \multicolumn{7}{|l|}{ Weekly work time } \\
\hline ( $\leq 40$ hours vs. $>40$ hours) & $-1.754^{* *}$ & $-0.096^{* *}$ & & & & \\
\hline \multicolumn{7}{|l|}{ Doctor-patient relationship } \\
\hline (Serious dissatisfaction vs. General dissatisfaction) & $2.535^{* *}$ & $0.169^{* *}$ & $2.273^{* *}$ & $0.159^{* *}$ & $1.287^{*}$ & $0.068^{*}$ \\
\hline Skill discretion & & & $-0.109^{*}$ & $-0.069^{*}$ & & \\
\hline Decision authority & & & $-0.110^{* *}$ & $-0.091^{* *}$ & $-0.137^{* *}$ & $-0.085^{* *}$ \\
\hline Psychological job demands & $0.068^{*}$ & $0.065^{*}$ & & & $0.230^{* *}$ & $0.118^{* *}$ \\
\hline Supervisor support & & & $-0.282^{* *}$ & $-0.090^{* *}$ & & \\
\hline Coworker support & & & & & $-0.592^{* *}$ & $-0.107^{* *}$ \\
\hline Extrinsic effort & $0.607^{* *}$ & $0.401^{* *}$ & $0.236^{* *}$ & $0.235^{* *}$ & $0.368^{* *}$ & $0.097^{* *}$ \\
\hline Reward & $-0.144^{* *}$ & $-0.074^{* *}$ & $-0.230^{* *}$ & $-0.199^{* *}$ & $-0.103^{*}$ & $-0.077^{*}$ \\
\hline Overcommitment & $0.464^{* *}$ & $0.154^{* *}$ & $0.287^{* *}$ & $0.101^{* *}$ & & \\
\hline
\end{tabular}

${ }^{*} p<0.05,{ }^{* *} p<0.01$. Age and gender were controlled in the model.

MBI-GS, Maslach Burnout Inventory-General Survey.

$E E$, Emotional exhaustion; $C Y$, Cynicism; $P E$, Professional efficacy.

$B$, Unstandardized coefficients.

Beta, Standardized coefficients.

Occupational stress measured by the JCQ and ERI was found to be the major factor associated with burnout $[4,42]$. Our results also indicate that all eight subscales in the JCQ and ERI had high correlations with the EE and CY burnout subscales, some of which were also associated with low PE; this is in agreement with studies previously cited in this manuscript. In our study, occupational stress explained $32 \%$ of variance in $\mathrm{EE}, 22 \%$ of variance in $\mathrm{CY}$, and $7 \%$ of variance in low PE. High extrinsic effort was the most powerful indicator of $\mathrm{EE}$ and $\mathrm{CY}$; high psychological job demands were the most robust indicator of low

Table 5 The effect of different variables on the variance in MBI-GS subscale scores

\begin{tabular}{llccc}
\hline Variables & & $\mathrm{EE}$ & $\mathrm{CY}$ & low PE \\
\hline Demographics & $\mathrm{R}^{2}$ & 0.01 & 0.01 & 0.01 \\
& $\Delta \mathrm{R}^{2}$ & 0.01 & 0.01 & 0.01 \\
& $\mathrm{~F}$ & $3.92^{* *}$ & $4.25^{* *}$ & 2.86 \\
Work situations & $\mathrm{R}^{2}$ & 0.13 & 0.11 & 0.07 \\
& $\Delta \mathrm{R}^{2}$ & 0.12 & 0.10 & 0.06 \\
& $\mathrm{~F}$ & $23.78^{* *}$ & $24.15^{* *}$ & $6.16^{* *}$ \\
Occupational stress & $\mathrm{R}^{2}$ & 0.45 & 0.33 & 0.14 \\
& $\Delta \mathrm{R}^{2}$ & 0.32 & 0.22 & 0.07 \\
& $\mathrm{~F}$ & $63.64^{* *}$ & $37.59^{* *}$ & $10.25^{* *}$ \\
\hline
\end{tabular}

**P<0.01.

$M B I-G S$, Maslach Burnout Inventory-General Survey.

$E E$, Emotional exhaustion; $C Y$, Cynicism; $P E$, Professional efficacy.

$\Delta R^{2}, R^{2}$ increase.

In step 1, demographics were added.

In step 2, work situations were added.

In step 3, occupational stress was added.
PE. A possible explanation for this result is that patient overload of doctors is especially serious in China because of the country's population base of 1.3 billion people. Overload of patients, together with the care model transition, has resulted in a high workload for doctors [41]. Many doctors have increased their extrinsic effort and psychological job demands to meet these changes. When the job demands exceed the capability of doctors, and their efforts exceed reward, the impact on their physical and mental health can lead to burnout $[13,19]$.

Previous studies have shown that relationships with superiors and colleagues are factors that influence burnout $[22,23,43]$. Poor relationships with superiors and colleagues may lead to feelings of exclusion and loneliness among doctors. Burnout may occur because there are no avenues for sharing their sense of frustration, or for receiving positive feedback from their peers. Conversely, good relationships with superiors and colleagues are protective factors [44]. Our study reported similar results; supervisor support and colleagues support has an important influence on burnout. The findings in this study contribute to our understanding that high levels of supervisor and colleague support has a positive effect on combating burnout among doctors. Reducing occupational stress and strengthening relationships with superiors and colleagues may decrease burnout and improve doctors' quality of life, as observed in other studies [19,41].

\section{Limitations}

Despite these merits, there are several limitations in the present study. First, participants in this study were limited 
to teaching hospitals of the China Medical University. Although the hospitals are dispersed across a range of city sizes, accurate representation of our study population may not be complete. Second, this study used a cross-sectional design, making it difficult to study causal relationships. Third, we have no information about the non-responders' characteristics, which may have introduced response bias. Fourth, this study was a preliminary investigation and as such did not address all medical specialties and the wide range of factors (e.g., sleep problems, and physical, cognitive, and emotional demands). Fifth, the doctor-patient relationship issue was measured using a single question; a more substantial questionnaire should have been used to address the doctor-patient relationship dynamic. These factors should be considered in further studies.

\section{Conclusions}

Occupational stress was found to be the most robust indicator of burnout among Chinese hospital doctors. Burnout was predicted by such factors as strong extrinsic effort, the most powerful indicator of $\mathrm{EE}$ and $\mathrm{CY}$, and strong psychological job demands, the most robust indicator of low PE. Our results highlight the importance of addressing extrinsic efforts to prevent $\mathrm{EE}$ and $\mathrm{CY}$, as well as addressing psychological job demands to prevent low PE. Our findings underscore the need for medical leaders to be aware of the risk of burnout. Efforts should be made to develop strategies to improve working conditions and reduce occupational stress, thereby mitigating the risk of burnout in doctors.

\section{Competing interests}

The authors declare that they have no competing interests.

\section{Authors' contributions}

HW designed the research, carried out data analysis, and wrote the paper. LW provided guidance in study design, organized the investigation, and is the corresponding author. LL, FG, and XZ provided help with the data collection, analysis, interpretation, and write-up. YW provided help with the data collection and interpretation. All authors read and approved the final manuscript.

\section{Acknowledgments}

The authors are thankful to the administrators in the study hospitals who helped to contact doctors for the survey, and to all the doctors who participated in this survey.

Received: 4 December 2012 Accepted: 27 August 2013

Published: 29 August 2013

\section{References}

1. Maslach C, Jackson SE, Leiter MP: Maslach Burnout Inventory, Manual 3rd Edition. Palo Alto, CA, USA: University of California, Consulting Psychologists Press; 1996.

2. Wright JG, Khetani N, Stephens D: Burnout among faculty physicians in an academic health science centre. Paediatr Child Health 2011, 16:409-413.

3. Garrosa E, Moreno-Jiménez B, Liang Y, González JL: The relationship between socio-demographic variables, job stressors, burnout, and hardy personality in nurses: an exploratory study. Int J Nurs Stud 2008, 45:418-427.

4. Schulz M, Damkröger A, Heins C, Wehlitz L, Löhr M, Driessen M, Behrens J, Wingenfeld K: Effort-reward imbalance and burnout among German nurses in medical compared with psychiatric hospital settings. J Psychiatr Ment Health Nurs 2009, 16:225-233.
5. Guido Lde A, Goulart CT, da Silva RM, Lopes LF, Ferreira EM: Stress and burnout among multidisciplinary residents. Rev Lat Am Enfermagem 2012, 20(6):1064-1071.

6. Ashtari Z, Farhady $Y$, Khodaee MR: Relationship between job burnout and work performance in a sample of Iranian mental health staff. Afr J Psychiatry (Johannesbg) 2009, 12:71-74.

7. Peterson U, Demerouti E, Bergström G, Samuelsson M, Asberg M, Nygren A: Burnout and physical and mental health among Swedish healthcare workers. J Adv Nurs 2008, 62:84-95.

8. Alacacioglu A, Yavuzsen T, Dirioz M, Oztop I, Yilmaz U: Burnout in nurses and physicians working at an oncology department. Psychooncology 2009, 18:543-548.

9. Ilhan MN, Durukan E, Taner E, Maral I, Bumin MA: Burnout and its correlates among nursing staff: questionnaire survey. J Adv Nurs 2008, 61:100-106.

10. Siu C, Yuen SK, Cheung A: Burnout among public doctors in Hong Kong: cross-sectional survey. Hong Kong Med J 2012, 18:186-192.

11. Selmanovic S, Ramic E, Pranjic N, Brekalo-Lazarevic S, Pasic Z, Alic A: Stress at work and burnout syndrome in hospital doctors. Med Arh 2011, 65:221-224.

12. Chopra S, Sotile WM, Sotile MO: Physician burnout. JAMA 2004, 291:633.

13. Liu XL, Sun HW, Jiang NZ: Present situation and prospect of doctor's burnout. Medicine and Society 2009, 22:53-55 (in Chinese).

14. Wang LJ, Chen CK, Hsu SC, Lee SY, Wang CS, Yeh WY: Active job, healthy job? Occupational stress and depression among hospital physicians in Taiwan. Ind Health 2011, 49:173-184.

15. Agerbo E, Gunnell D, Bonde JP, Mortensen PB, Nordentoft M: Suicide and occupation: the impact of socio-economic, demographic and psychiatric differences. Psychol Med 2007, 37:1131-1140.

16. Schernhammer ES, Colditz GA: Suicide rates among physicians: a quantitative and gender assessment (meta-analysis). Am J Psychiatry 2004, 161:2295-2302.

17. Li L: Social Medicine. Beijing: People's medical publishing house; 2007:155.

18. Zhang $Y$, Feng $X$ : The relationship between job satisfaction, burnout, and turnover intention among physicians from urban state-owned medical institutions in Hubei China: a cross-sectional study. BMC Health Serv Res 2011, 11:235.

19. Wang $\mathrm{H}$, Zhang $\mathrm{N}$ : Analysis on the status of occupational burnout among doctors. Zhong Guo Jian Kang Xin Li Xue Za Zhi 2008, 16:397-399 (in Chinese).

20. Maccacaro G, Di Tommaso F, Ferrai P, Bonatti D, Bombana S, Merseburger A: The effort of being male: a survey on gender and burnout. Med Lav 2011, 102:286-296.

21. Piko BF: Burnout, role conflict, job satisfaction and psychosocial health among Hungarian health care staff: a questionnaire survey. Int J Nurs Stud 2006, 43:311-318.

22. Escribà-Agüir V, Martín-Baena D, Pérez-Hoyos S: Psychosocial work environment and burnout among emergency medical and nursing staff. Int Arch Occup Environ Health 2006, 80:127-133.

23. Karasek $\mathrm{R}$, Theorell $\mathrm{T}$ : Healthy work: stress, productivity, and the reconstruction of working life. New York: Basic Books; 1990.

24. Tsai FJ, Chan CC: Occupational stress and burnout of judges and procurators. Int Arch Occup Environ Health 2010, 83:133-142.

25. Siegrist J: Adverse health effects of high-effort/low-reward conditions at work. J Occup Health Psychol 1996, 1:27-41.

26. Siegrist J, Starke D, Chandola T, Godin I, Marmot M, Niedhammer I, Peter R: The measurement of effort-reward imbalance at work: European comparisons. Soc Sci Med 2004, 58:1483-1499.

27. Zhu W, Wang ZM, Wang MZ, Lan YJ, Wu SY: Occupational stress and job burnout in doctors. Sichuan Da Xue Xue Bao 2006, 37:281-283 (in Chinese).

28. Smith DR, Tang S: Nursing in China: historical development, current issues and future challenges. Int J Nurs Stud 2004, 5:16-20.

29. Wang $Y$, Chang Y, Fu JL, Wang L: Work-family conflict and burnout among Chinese female nurses: the mediating effect of psychological capital. BMC Public Health 2012, 12:915.

30. Zhu W, Wang ZM, Wang MZ, Lan YJ, Wu SY: Job burnout and contributing factors for nurses. Sichuan Da Xue Xue Bao 2006, 37:632-635 (in Chinese).

31. Wu S, Zhu W, Wang Z, Wang M, Lan Y: Relationship between burnout and occupational stress among nurses in China. J Adv Nurs 2007, 59:233-239.

32. Wu H, Zhao Y, Wang JN, Wang L: Factors associated with occupational stress among Chinese doctors: a cross-sectional survey. Int Arch Occup Environ Health 2010, 83:155-164. 
33. Gao $Y Q$, Pan $B C$, Wu H, Wang L: A survey study on depressive symptoms of nurses and their correlation with nurse-patient relationship. Journal of China Medical University 2011, 40:547-548 (in Chinese).

34. Yang WJ, Li J: Measurement of psychosocial factors in work environment: application of two models of occupational stress. Zhong Hua Lao Dong Wei Sheng Zhi Ye Bing Za Zhi 2004, 22:422-426 (in Chinese).

35. Li J, Yang W, Cheng Y, Siegrist J, Cho SI: Effort-reward imbalance at work and job dissatisfaction in Chinese healthcare workers: a validation study. Int Arch Occup Environ Health 2005, 78:198-204.

36. National Bureau of Statistics: China Statistical Yearbook [M]. Beijing: China Statistics Press; 2011

37. Zhou ZT: Investigation on job burnout status of policemen of one public security sub- bureau. China Journal of Health Psychology 2009, 17:11-18.

38. Al-Dubai SA, Rampal KG: Prevalence and associated factors of burnout among doctors in Yemen. J Occup Health 2010, 52:58-65.

39. Gabbe SG, Melville J, Mandel L, Walker E: Burnout in chairs of obstetrics and gynecology: diagnosis, treatment, and prevention. Am J Obstet Gynecol 2002, 186:601-612.

40. Wang Y, Liu L, Wang JN, Wang L: Work-family conflict and burnout among Chinese doctors: the mediating role of psychological capital. J Occup Health 2012, 54:232-240.

41. Liu L, Chang Y, Fu JL, Wang JN, Wang L: The mediating role of psychological capital on the association between occupational stress and depressive symptoms among Chinese physicians: a cross-sectional study. BMC Public Health 2012, 12:219.

42. Huang JM, LIU HC, Song XR: The research about present status and their relationship of occupational stress and job burnout in medical personnel. Int J Nurs 2010, 29:492-494.

43. McManus IC, Winder BC, Gordon D: The causal links between stress and burnout in a longitudinal study of UK doctors. Lancet 2002, 359:2089-2090,

44. Ozyurt A, Hayran O, Sur H: Predictors of burnout and job satisfaction among Turkish physicians. Q J Med 2006, 99:161-169.

doi:10.1186/1471-2458-13-786

Cite this article as: Wu et al:: Factors associated with burnout among

Chinese hospital doctors: a cross-sectional study. BMC Public Health 2013 13:786

\section{Submit your next manuscript to BioMed Central and take full advantage of:}

- Convenient online submission

- Thorough peer review

- No space constraints or color figure charges

- Immediate publication on acceptance

- Inclusion in PubMed, CAS, Scopus and Google Scholar

- Research which is freely available for redistribution 